\title{
Thoracic Spinal Epidural Abscess Caused by Salmonella Typhi
}

\author{
-Case Report-
}

\author{
Saad Hamdan AbDullah, Osama Abu AtA*, and Nael El-AdWAN
}

Departments of Neurosurgery and ${ }^{*}$ Infectious Disease, Islamic Hospital, Amman, Jordan

\begin{abstract}
A 56-year-old man presented with a rare spinal epidural abscess manifesting as attacks of back pain associated with fever, weight loss, generalized weakness and fatigability, and constipation. He had multiple skin pustules in the last 4 months treated with oral amoxicillin. He had suffered diabetes mellitus for the last 5 years and was insulin dependent. Physical examination found slight paraparesis with sensory loss around the nipple and sphincteric urgency, and diabetic retinopathy. Magnetic resonance imaging showed edematous T2, T3, and T4 vertebral bodies, and narrow enhanced T3-4 disk space with a soft tissue enhanced mass mostly anterior to the spinal cord and indenting the cord. T3-4 costotransversectomy was performed to remove the extradural mass and evacuate the intradiscal material. Histological examination of the bone found osteomyelitis, and culture of the soft tissue showed Salmonella typhi sensitive to ceftriaxone and ciprofloxacin. Intravenous ceftriaxone administration was started, and the patient was discharged after 6 days in good condition. The outcome of spinal epidural abscess is devastating unless recognized and treated early. The present case of spinal epidural abscess in the thoracic spine caused by Salmonella typhi infection illustrates the importance of cultures to assess the drug sensitivity of the specific strain detected and adjusting the treatment accordingly.
\end{abstract}

Key words: spinal epidural abscess, Salmonella typhi, costotransversectomy, medical treatment, neuroimaging

\section{Introduction}

The incidence of spinal epidural abscess is increasing due to several factors: routine use of spinal epidural anesthesia; intravenous drug abuse, although rare in the Middle East; the increasing number of immune-suppressed patients; and the increasing number of elderly in the general population. ${ }^{3,4,6,14)}$ Modern noninvasive modalities of investigation such as magnetic resonance (MR) imaging are also leading to increased rates of identification of spinal epidural abscess. ${ }^{2,9)}$ On the other hand, the combination of vertebral osteomyelitis and epidural abscess is rare, accounting for only $1-4 \%$ of all bone infections. ${ }^{11)}$

Here, we report an unusual case of epidural abscess and vertebral osteomyelitis in the dorsal spine caused by Salmonella typhi.

Received August 17, 2004; Accepted December 3, 2007

\section{Case Report}

A 56-year-old man presented with back pain in the interscapular area occurring as repeated attacks for the last 3 months, sometimes radiating to the anterior chest wall, associated with attacks of fever but no chill or rigor. He had lost around $5 \mathrm{~kg}$ body weight in the last 3 months with a feeling of generalized weakness and fatigability. The patient also reported attacks of constipation but no abdominal pain. He also mentioned multiple skin pustules in the last 4 months for which he took oral antibiotics (amoxicillin $500 \mathrm{mg} \times 3$ ). He had suffered diabetes mellitus for the last 5 years and was insulin dependent. He had slight paraparesis with sensory loss around the nipple and sphincteric urgency, but no other physical abnormality except for diabetic retinopathy. No murmur or organomegaly was found.

Laboratory examination showed leukocytosis, white blood cell count of $21.8 \times 10^{3} / \mu \mathrm{l}$, predominantly neutrophilic; high erythrocyte sedimentation rate of $95 \mathrm{~mm} / \mathrm{hr}$; positive C-reactive protein level of $19 \mathrm{mg} / \mathrm{l}$; slight increase in liver enzymes; 

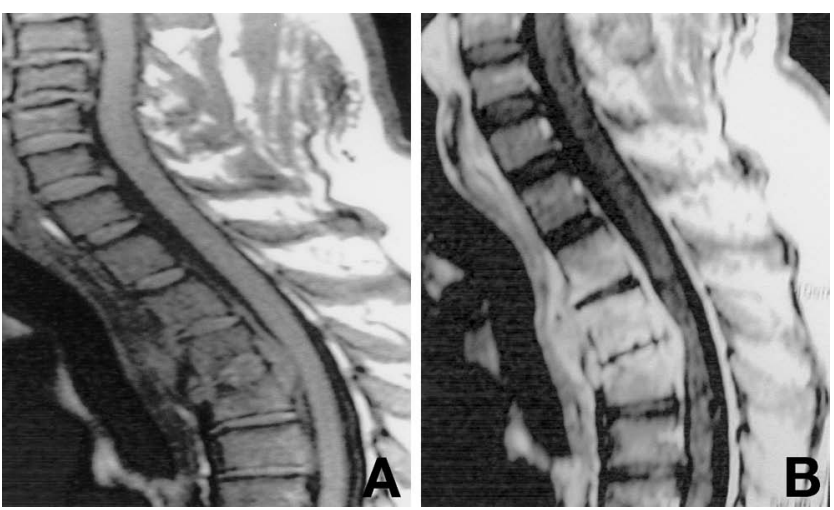

Fig. 1 (A) $T_{1}$-weighted magnetic resonance (MR) image of the cervicothoracic junction showing anterior epidural compression and the destroyed disk space. (B) $\mathrm{T}_{1}$-weighted $M R$ image with contrast medium showing enhancement in the disk space and the soft tissue.
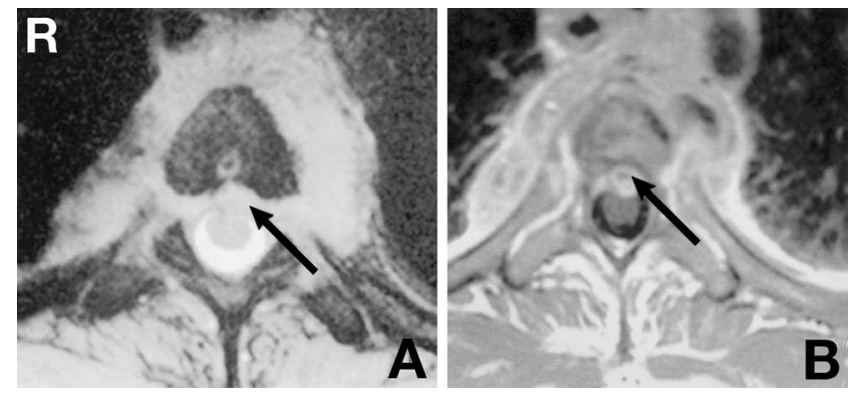

Fig. 2 (A) Axial $T_{2}$-weighted magnetic resonance (MR) image of the disk space and soft tissue mass. The arrow shows the epidural mass and represents the direction of the surgical approach. (B) $T_{1}$-weighted $M R$ image with contrast medium showing the enhanced mass. The arrow is also pointing to the epidural mass.

positive reaction for hepatitis $B$ surface antigen, negative reaction for hepatitis $\mathrm{B}$ e antigen, positive reaction for antibody to the hepatitis $\mathrm{B}$ e antigen; and negative reaction for human immunodeficiency virus. Blood culture was negative three times.

Abdominal ultrasonography showed multiple gallstones but no gallbladder wall edema. Spine MR imaging showed edematous $\mathrm{T} 2, \mathrm{~T} 3$, and $\mathrm{T} 4$ vertebral bodies, and narrow enhanced T3-4 disk space with a soft tissue enhanced mass mostly anterior to the spinal cord and indenting the cord (Figs. 1 and 2).

The neurosurgery team was consulted immediately and the patient was prepared for surgery the following day. T3-4 costotransversectomy was per- formed to remove the extradural mass and evacuate the intradiscal material. Histological examination of the bone found osteomyelitis, and culture of the soft tissue showed Salmonella species, which was sensitive to ceftriaxone and ciprofloxacin.

Intravenous ceftriaxone administration was started, and the patient was discharged after 6 days in good condition, with intravenous ceftriaxone treatment continued for at least 6 weeks.

\section{Discussion}

Typhoid fever is a systemic infection caused by the bacterium Salmonella enterica, serotype typhi, which is a human-specific organism and an important cause of disease and mortality all over the world.7) Salmonella epidural abscess is rare, and mainly occurs in immune-compromised patients such as with sickle cell anemia or acquired immunodeficiency syndrome. ${ }^{10,15,17)}$ The most common location for vertebral osteomyelitis caused by Salmonella is the lumbar spine followed by the cervical spine. ${ }^{1,5,8)}$ The present case of epidural abscess and osteomyelitis caused by Salmonella infection was located in the thoracic spine.

Our patient presented with back pain and fever, which are the most common manifestations. ${ }^{15)}$ Such presentation should always raise the possibility of epidural abscess. Our patient had gross neurological deficits, which should raise even more concern for this disease. The MR imaging findings in our case were similar to those reported elsewhere, ${ }^{2,9)}$ with narrowing of the disk space and enhanced space and epidural mass. We think that routine use of MR imaging in our hospital led to early detection and prevented devastating neurological sequelae in our patient. ${ }^{13)}$

No direct source of infection could be identified in our patient, but there were multiple risk factors including diabetes mellitus, recurrent skin infections, and living in an endemic area. The most common organism to cause epidural abscess is Staphylococcus, and rarely Gram-negative organisms. ${ }^{11,17)}$ The failure to obtain a positive blood culture in our case is mostly due to the fact that the patient had received oral antibiotics for his skin infections.

The most alarming issue in the treatment of Salmonella is the emergence of antibiotic resistance, mainly in South East Asia, Middle East, and Africa. Salmonella typhi used to be treated with chloramphenicol, amoxicillin, and trimethoprim-sulfamethoxazole. However, high resistance to these agents is now common, so agents like third generation cephalosporins and fluoroquinilones are the 
agents of choice, as used in our case. Unfortunately, cases of multi-drug resistant salmonellosis are known, even to the newer agents, which indicates the importance of using cultures to assess the drug sensitivity of the specific strain detected and adjusting the treatment according to the sensitivity. ${ }^{8,17)}$

Surgical treatment was chosen for our patient for two reasons: the cord compression that needed to be decompressed, and the need to obtain a tissue culture since the blood culture was negative three times. ${ }^{12,16)}$ The choice of costotransversectomy provided an excellent route to reach the anteriorly located mass and disk space without disturbing the spinal cord.

\section{References}

1) Akagi S, Shimada H, Kato I, Saito T, Ogawa R: Cervical spondylitis and epidural abscess caused by Salmonella enteritidis with tetraplegia. Orthopedics 21: 1289-1291, 1998

2) Angtuco EJ, McConnell JR, Chadduck WM, Flamgau S: MR imaging of spinal epidural sepsis. AJR Am J Roentgenol 149: 1249-1253, 1987

3) Carey ME: Infections of the spine and spinal cord, in Youmans JR (ed): Neurological Surgery, part XI, Infection, 3rd ed. Philadelphia, WB Saunders, 1996, pp 3759-3781

4) Chao D, Nanda A: Spinal epidural abscess: a diagnostic challenge. Am Fam Physician 65: 1341-1346, 2002

5) Colle I, Peeters P, Le Roy I, Diltoer M, D'Haens J: Epidural abscess: case report and review of the literature. Acta Clin Belg 51: 412-416, 1996

6) Danner RL, Hartman BJ: Update on spinal epidural abscess: 35 cases and review of the literature. Rev Infect Dis 9: 265-274, 1987

7) de la Fuente Aguado J, Arzuaga Torre JA, Yusta Izquierdo A, Garcia Andrade L, Martinez Lopez de Letona J: [Spinal epidural abscess. 8 years' experience]. Rev Clin Esp 191: 264-266, 1992 (Spa, with Eng abstract)
8) Dolan SA, Everett ED, Harper MC: Salmonella vertebral osteomyelitis treated with cefotaxime. Arch Intern Med 147: 1667-1668, 1987

9) Erntell M, Holtas S, Norlin K, Dahlquist E, NilssonEhle I: Magnetic resonance imaging in the diagnosis of spinal epidural abscess. Scand J Infect Dis 20: 323-327, 1988

10) Gardner RV: Salmonella vertebral osteomyelitis and epidural abscess in a child with sickle cell anemia. Pediatr Emerg Care 1: 87-89, 1985

11) Kaufman DM, Kapler JG, Litman N: Infectious agents in spinal epidural sepsis. Neurology 30: 844-850, 1980

12) Kuiters RR, Douma G, Hekster RE: Spinal epidural abscess. Report of two cases. Clin Neurol Neurosurg 89: 255-260, 1987

13) Lindner A, Warmuth-Metz M, Becker G, Toyka VV: Iatrogenic spinal epidural abscesses: early diagnosis essential for good outcome. Eur J Med Res 2: 201-205, 1997

14) Mahendru V, Bacon DR, Lema MJ: Multiple epidural abscesses and spinal anesthesia in a diabetic patient. Case report. Reg Anesth 19: 66-68, 1994

15) McGee-Collett M, Johnston IH: Spinal epidural abscess: presentation and treatment. A report of 21 cases. Med J Aust 155: 14-17, 1991

16) Rea GL, McGregor JM, Miller CA, Miner ME: Surgical treatment of the spontaneous spinal epidural abscess. Surg Neurol 37: 274-279, 1992

17) Rigamonti D, Liem L, Sampath $P$, Knoller N, Namaguchi Y, Schreibman DL, Sloan MA, Wolf A, Zeidman S: Spinal epidural abscess: Contemporary trends in etiology, evaluation, and management. Surg Neurol 52: 189-197, 1999

Address reprint requests to: Nael El-Adwan, M.D., Department of Neurosurgery, Islamic Hospital, P.O. Box 2414, Amman 11181, Jordan. e-mail: saadhamdan1@yahoo.com 